\section{Gilbert's Syndrome}

SIR,-The following comments relate to the leading article on Gilbert's syndrome (4 May, p. 256). You correctly state that the syndrome of chronic, mild unconjugated hyperbilirubinaemia without overt signs of haemolysis is commonly observed, the pathogenesis is unclear but certainly multiple, and the relation between signs and symptoms is obscure.

I wish to take issue with the recommendation for "full investigation" of such patients. One must differentiate between clinical diagnosis and research studies of the pathogenesis of the syndrome in an individual patient. Our experience with over 250 patients with this syndrome permits the following conclusions: (1) With the exception of patients with increased production of bile pigment from sources other than mature, circulating erythrocytes, the syndrome is benign, nonprogressive, and entirely cosmetic. (2) In all cases hepatic histology is not diagnostic and is usually normal even in patients with posthepatitic unconjugated hyperbilirubinaemia. Liver biopsy is not required for diagnosis and pathologic overinterpretation frequently adds to the distressingly high frequency of the erroneous diagnosis of chronic active liver disease and subsequent injudicious treatment.

Patients with liver disease who occasionally manifest this syndrome have always had abundant clinical and laboratory evidence of liver damage.

The physician should easily make the correct diagnosis on clinical grounds with the aid of conventional hepatic and haematological studies. The treatment is repeated reassurance regarding the cosmetic nature of the syndrome, and patients should be urged to full activity, normal diet, and enjoyment of life even when the syndrome follows hepatitis. It should be stressed that icterus may be increased by exercise, ethanol ingestion, infection, and medications, including oral contraceptive agents, but that these changes are also solely cosmetic. Repeated liver function tests are not desirable and only add to the functional symptomatology manifested by most patients.

The clinical investigator is confronted with a challenging problem in pathophysiology which will require new techniques of structural and functional nature. Extensive studies in either or both areas may be performed, but the investigator's goals and approach should not be confused with those of the physician in these cases.-I am, etc.,

IrWin M. Arias.

Department of Medicine, Albert Einstein College of Medicine,

\section{Anaesthesia for Insertion of Arteriovenous Cannulae}

SIR,-I was interested in Dr. Doreen Browne's letter on anaesthesia for shunt insertion (18 May, p. 432). In Cambridge intermittent dialysis is performed only prior to transplantation, and then until the onset of adequate transplant function. The vast majority of patients on the programme are referred from dialysis units elsewhere. Fairly often many of the usual cannula sites have already been used up.
We are reluctant to submit our patients to a general anaesthetic for shant insertion, and until recently most of these have been inserted with local infiltration of $2 \%$ lignocaine without adrenaline. Of the eight arm cannulae most recently inserted six were inserted under local anaesthesia, using the Bier technique as follows. ${ }^{12}$

(1) A Ghord needle is inserted into a vein either on the dorsum of the hand or in the cubital fossa pointing distally and is taped in position.

(2) The limb is then elevated for five minutes to promote venous drainage. A lightweight Esmarch bandage could be used for this purpose, though I have not found it necessary.

(3) A tourniquet applied to the upper arm is then inflated to a pressure $50 \mathrm{~mm}$. $\mathrm{Hg}$ higher than the patient's systolic B.P. and the limb returned to the horizontal position.

(4) Between 40 and $60 \mathrm{ml}$. of $0.5 \%$ lignocaine without adrenaline is then injected intravenously via the Ghord needle. A blotchy appearance is produced in the skin as the anaesthetic takes effect.

The appropriate artery and vein are then exposed and cannulated in the usual fashion. The loop of the shunt is then buried and the vessel irrigated with heparinized saline $(5,000$ units per $500 \mathrm{ml}$. saline).

I have found this method to give completely satisfactory anaesthesia of the arm below the level of the tourniquet. This greatly facilitates dissection of the radial artery in the deeper planes in the middle and upper forearm. I have also found that it frequently outlines veins which would not otherwise have been obvious.

The maximum "tourniquet time" in the six cases done so far has been $1 \frac{1}{2}$ hours. Only one patient has complained of discomfort due to the tourniquet. This can easily be relieved using a double cuff. When cannulation has been satisfactorily completed the tourniquet pressure is reduced by $50 \mathrm{~mm}$. $\mathrm{Hg}$ at a time at intervals of three to four minutes. The resulting blood flows have been very good, no doubt owing to the resultant hyperaemia.

I had used this form of anaesthetic for more than 60 orthopaedic and other manipulations before applying it to cannulation. I have never seen in any of these cases any systemic upset following release of lignocaine into the circulation. I feel that this is a useful method of producing anaesthesia for cannulation, particularly for second or third operations and also for patients whose veins are difficult to find.-I am, etc.,

Addenbrooke's Hospital,
Cambridge.

$$
\text { ROBERT MCMillaN. }
$$

\section{REFERENCES}

'Bier, A., Arch. Klin. Chir., 1908, 86, 1007.
2 Holmes, C. M., Lancet, 1963, 1, 245.

\section{Stomal Obstruction after Gastroenterostomy}

SIR,-The complication of stomal obstruction after retrocolic gastroenterostomy described by Mr. I. G. M. Cleator and others (1 June, p, 530) is another argument in favour of pyloroplasty rather than gastroenterostomy as the better gastric drainage operation in the conservative surgery of duodenal ulcer, although for large active ulcers gastroenterostomy may be the necessary alternative.
It is to be noted, furthermore, that in their comments on the prevention of stomal obstruction the authors do not include anterior gastroenterostomy instead of the retrocolic operation. The anterior method will certainly prevent this complication, and the long-term results on anterior gastroenterostomy and vagotomy for chronic duodenal ulcer are as good as or better than those of the retrocolic operation. ${ }^{2}-$ I am, etc.,

London $\mathbf{W} .1$.

Grorge Qvist.

\section{REFERENCES}

Swynnerton, B. F. A., Gastroenterologia (Basel) Tanner, N. C., Proc. Roy. Soc. Med., 1967, 60, 221.

\section{Voluntary Sterilization in the Male}

SIR, - While welcoming your excellent leader (1 June, p. 508), I should like to take you up on three points. You state that if a surgeon performs a vasectomy for reasons unconnected with health he is "liable to prosecution under laws that date back to the thirteenth century." You are presumably referring to the law of mayhem. It is worth pointing out that a mayhem, or maim, is a mutilation which will render a man unfit for military service. Vasectomy does not do this. Secondly, you state that "the surgeon still finds the situation uncomfortable." This is certainly not true of the numerous surgeons known to the Simon Trust who are regularly performing these operations. Finally, you press for a change in the law. What change? Vasectomy is not against the law any more than is a cosmetic operation.-I am, etc.,

$$
\begin{gathered}
\text { L. N. JACKSON, } \\
\text { Hon. Director, } \\
\text { Simon Population Trust } \\
\text { Voluntary Sterilization Project. }
\end{gathered}
$$

London S.W.1.

SIR,-Your leading article on voluntary sterilization in the male (1 June, p. 508) is unduly alarming. In November 1960 the Medical Defence Union obtained and published an opinion from leading counsel on the English law on the legality of sterilization of the male or female. This opinion was to the effect that an operation for sterilization was not unlawful, whether it was carried out on therapeutic or eugenic grounds, or for any other reason, provided there was valid consent to the operation by the patient concerned

Since the publication of counsel's opinion no one in authority has expressed a contrary view and there has been no suggestion that any surgeon who performs a vasoligation is in danger of prosecution. Over 1,500 vasoligations have been carried out to the knowledge of the Simon Population Trust since it set up its sterilization project two years ago.

The union does not believe that any good would come of a test case, even if one could be brought-and this would not be easy. Still less does the union consider that legislation is required to declare that a particular operation is lawful. The Abortion Act does not inspire confidence in the ability of Parliament to grapple with medical subjects.-I am, etc.,

Philip H. Addison,

London W.C.1. 